SocioEconomic Challenges, Volume 4, Issue 4, 2020

ISSN (print) - 2520-6621, ISSN (online) - 2520-6214

\title{
Transparency As A Way Of Attaining Quality, Safety And Optimal Food Purchases
}

\author{
https://doi.org/10.21272/sec.4(4).48-62.2020.
}

Martina Dove, ORCID: https://orcid.org/0000-0003-0750-0166.

User Researcher, Microsoft Cognitive Services (via Robert Half), Seattle, USA

Adhithya Balasubramanian, ORCID: https://orcid.org/0000-0001-9215-9569

Research Intern, Infinite Sum Modelling LLC, Seattle, USA

Badri G. Narayanan, ORCID: https://orcid.org/0000-0001-9628-8173

Founder Director, Infinite Sum Modelling LLC, Seattle, USA

\begin{abstract}
The present extensive literature analysis and interview study, with consumers living in Washington state, USA, set out to explore consumers' perceptions of quality, safety, and transparency and see how these influence shopping preferences. Literature review included global studies which looked at food transparency, safety, quality, food certifications and environmental concerns. The findings indicate that organic foods are often linked to health, nutrition, environmental concerns as well as presence of children, and quality is measured by assessing freshness, taste, nutrition and traceability. Consumers are increasingly interested in knowing where their food comes, expressing willingness to switch to more transparent brands. Additionally, welfare of animals reared for consumption and support for local agriculture is also important to consumers, who are willing to pay more for organic products. However, this willingness also depends on demographic factors, such as gender, educational level, income or age. The results of the interviews yielded similar findings. Participants were guided by subjective perceptions of food quality and concerns driven by personal values and ethical and environmental considerations. Food safety was confusing for almost all of the consumers in this study, with many expecting stores to provide safe foods. The study utilized a concept testing method to evaluate the concept of food transparency and examine how it compares against the established food certifications (organic and free-range). Consumers exhibited trust in organic labels, expecting organic farming to ensure good farming practices and quality of life for animals reared for consumption; however, they were also aware that this trust is based on assumptions. As a result, they were receptive to more accurate and transparent information, that could guide their decisions and give them more certainty. Transparency concept was seen as a useful tool in identifying quality products that align with personal values, such as supporting local food producers, and was received well with consumers in the present study.
\end{abstract}

Keywords: food transparency, food quality, food safety, ethics, values, environment, agriculture, grocery shopping. food.

JEL Classification: Q0, Q1,Q10, Q11, Q19.

This work is licensed under a Creative Commons Attribution 4.0 International License.

Cite as: Dove, M., Balasubramanian, A., Narayanan, B.G. (2020). Transparency As A Way Of Attaining Quality, Safety And Optimal Food Purchases. SocioEconomic Challenges, 4(4), 48-62. https://doi.org/10.21272/sec.4(4).48-62.2020.

(C) The Authors, 2020. This article is published with open access at Sumy State University.

\section{Introduction}

With growing concerns over food fraud and food safety and consumers' interest in detailed information about the foods they are consuming, which can help guide more informed choices, the value of brands implementing 
transparency is a topic of growing importance. De Jonge et al. (2008), through their exploratory study, showed very high importance of consumer confidence in the safety of food and the crucial interrelation with consumer behavior. In the absence of a better solution, consumers generally use food certification and labeling to guide their food choices. However, if such a solution existed, would they be more inclined to use it as a way of assessing food quality and safety?

The broad aims of this research are to explore literature assessing the importance and complexities involving food transparency as a key tool in the food market along with an exploratory study on food consumers' opinions on food quality and safety, as well as introduce a concept of 'food transparency'. We aim to see what food consumers might think about it and how would they feel being able to access transparent information about the foods they buy easily. Additionally, how would this information guide their purchasing decisions compared to traditional food certifications and labeling, such as organic and free-range? In order to achieve these aims, in addition to a comprehensive and critical review of literature, we conducted interview studies with six grocery consumers in Washington State in the U.S., focusing on various aspects of perceptions in food transparency, quality and safety. Our results broadly suggest that consumers place trust in labeling for organic foods and free-range, while at the same time they are willing to try better ways of assessing the foods they consume. This is because they are aware that their trust is based on assumptions rather than facts. Additionally, food safety can be an overwhelming topic, and consumers may purposely be relying on the stores to make sure the food is safe to avoid having to think about it.

The uniqueness of our study stems from two observations; first, to our knowledge, there is no such comprehensive coverage of literature to synthesize the concept of food transparency, quality, safety in the context of optimal food purchases as our title suggests; second, the in-depth interview discussions we conducted shed light on this topic in a way that other studies we have reviewed have not shown so far.

This paper is organized as follows: In section 2, we explain our methods; literature review of the available research, as well as the results of the interviews we conducted with consumers based in the state of Washington, USA. In section 3 we provide a discussion on the findings and in section 4 we discuss the limitations and implications of this research.

\section{Methodology}

In this section we examine different strands of literature and discuss findings of our interview study with food consumers. The methodology section consists of two parts. Part one presents extensive literature review into food consumers' behaviors and beliefs, as well as decisions that guide their shopping preferences. Additionally, information on consumers' opinions regarding food transparency.

The second part of the methodology section reports the results of the interview study with food consumers residing in the state of Washington, USA. The interview study consisted of unstructured exploration of participants' food shopping behaviors, thoughts and preferences, as well as a concept testing stage. In this stage, food transparency concept was introduced and explored, in order to see how food transparency may affect consumers' shopping behaviors.

\subsection{Literature review}

We examined the available literature looking into what guides consumers when it comes to food quality, safety, transparency and what values and perceptions may guide their purchase decisions and willingness to pay more for foods. Table 1 shows a list of research studies we considered and their findings, as well as the geographical locations of the research. No big differences can be observed when it comes to countries. However, some of the literature on the role of personal values in shopping decisions, concerns about the environment and support for local food producers was readily available for European countries and the United States but not so much for the rest of the world. This may suggest that geographical differences exist in terms of how consumers think about food and what drives their shopping decisions and that, in some countries, certain issues connected to food are more prevalent, leading to more research on those topics. 
Table 1. Comparison of the international literature on food quality, safety, certifications and environmental concerns

\begin{tabular}{|c|c|c|}
\hline Main findings & Authors & Country \\
\hline \multirow{4}{*}{$\begin{array}{l}\text { Food quality assessed by looking at freshness, } \\
\text { taste, nutrition, and traceability. }\end{array}$} & Chamhuri and Batt (2015) & Malaysia \\
\hline & Petrescu et al. (2020) & Belgium, Romania \\
\hline & van Rijswijk and Frewer (2008) & Germany, France, Italy, Spain \\
\hline & Wandel and Bugge (1997) & Norway \\
\hline \multirow{4}{*}{$\begin{array}{l}\text { Certain values guide consumers' food } \\
\text { preferences, and products reflecting these } \\
\text { values (e.g., environmental concerns) are often } \\
\text { received positively. }\end{array}$} & Lerro et al. (2019) & Italy \\
\hline & Ricci et al. (2018) & Italy \\
\hline & Raygor (2016) & United States of America \\
\hline & Yu et al. (2017) & United States of America \\
\hline \multirow{2}{*}{$\begin{array}{l}\text { Organic foods are linked to health, nutrition, } \\
\text { better taste, environmental concerns, as well as } \\
\text { situational factors (e.g. presence of children in } \\
\text { the home). }\end{array}$} & Dumortier et al. (2017) & United States of America \\
\hline & Lee (2016) & United States of America \\
\hline \multirow{4}{*}{$\begin{array}{l}\text { Reliance on certification labels (organic, free } \\
\text { range, halal etc.) guide food shopping decisions } \\
\text { on personal or religious grounds. }\end{array}$} & Neff et al. (2019) & United States of America \\
\hline & Savelli et al. (2019) & Italy \\
\hline & Mayfield et al. (2007) & Great Britain, Italy, Sweden \\
\hline & Shafie and Othman 2006 & Malaysia \\
\hline $\begin{array}{l}\text { Food certification label are not always clear to } \\
\text { consumers and as such, consumers fail to notice } \\
\text { them. }\end{array}$ & My et al. (2017) & Vietnam \\
\hline \multirow{3}{*}{$\begin{array}{l}\text { Willingness to pay for certified foods found to } \\
\text { be related to income, age, educational level, } \\
\text { gender, level of consumption, and awareness of } \\
\text { traceability. }\end{array}$} & $\mathrm{Xu}$ and $\mathrm{Wu}(2010)$ & China \\
\hline & Angulo and Gil (2007) & Spain \\
\hline & Lagerkvist and Hess (2011) & $\begin{array}{c}\text { Various European countries, United States of } \\
\text { America, Australia }\end{array}$ \\
\hline \multirow{2}{*}{$\begin{array}{l}\text { Organic certification does not always inspire } \\
\text { consumers' trust and influence purchase } \\
\text { frequency, nor does it predict willingness to pay } \\
\text { more for certified products. }\end{array}$} & Dumortier et al. (2017) & United States of America \\
\hline & Xu \& Wu (2010) & China \\
\hline \multirow{2}{*}{$\begin{array}{l}\text { Millennial consumers especially concerned with } \\
\text { social and environmental concerns. }\end{array}$} & Yu et al. (2017) & United States of America \\
\hline & Lerro et al. (2019) & Italy \\
\hline \multirow{3}{*}{$\begin{array}{l}\text { Consumers like local produce because they } \\
\text { connect it to greater freshness and quality and } \\
\text { want to support local agriculture. }\end{array}$} & Brown (2003) & United States of America \\
\hline & Vossen (1992) & United States of America \\
\hline & Yu et al. (2017) & United States of America \\
\hline \multirow{3}{*}{$\begin{array}{l}\text { Consumers increasingly wanting to know where } \\
\text { their food comes from, expressing the desire for } \\
\text { food transparency and information on animal } \\
\text { welfare and safety. }\end{array}$} & Raygor (2016) & United States of America \\
\hline & Yu et al. (2017) & United States of America \\
\hline & Centre for Food Integrity (2015) & United States of America \\
\hline \multirow{2}{*}{$\begin{array}{l}\text { Consumers see animal welfare as an ethical } \\
\text { issue when it comes to animals raised for } \\
\text { consumption. }\end{array}$} & Mayfield et al. (2007) & Great Britain, Italy, Sweden \\
\hline & Lagerkvist and Hess (2011) & $\begin{array}{c}\text { Various European countries, United States of } \\
\text { America, Australia }\end{array}$ \\
\hline Consumers interlink quality and safety & van Rijswijk and Frewer (2008) & Germany, France, Italy, Spain \\
\hline \multirow{4}{*}{$\begin{array}{l}\text { Consumers see food additives, genetically } \\
\text { modified food and pesticides as undesirable and } \\
\text { prefer foods without hormones. }\end{array}$} & Brockman and Beeren (2011)* & United States of America \\
\hline & My et al. $(2017)^{* *}$ & Vietnam \\
\hline & Bellows et al. (2010)*** & United States of America \\
\hline & Stanton $(2018)^{* * * *}$ & United States of America \\
\hline \multirow{4}{*}{$\begin{array}{l}\text { Food outbreaks, which end up in the media } \\
\text { affect consumers' trust in food safety, leading to } \\
\text { decrease in consumer confidence and higher } \\
\text { perception of risk. }\end{array}$} & $\mathrm{Xu}$ and $\mathrm{Wu}(2010)$ & China \\
\hline & Angulo and Gil (2007) & Spain \\
\hline & Chen (2008) & Taiwan \\
\hline & De Jonge et al. (2007) & Netherlands \\
\hline \multirow{3}{*}{$\begin{array}{l}\text { Consumers expressed desire for transparency, } \\
\text { which may influence brand integrity and } \\
\text { encourage brand switching. }\end{array}$} & Cambier and Poncin (2020) & Belgium \\
\hline & Label Insights (2016) & United States of America \\
\hline & Shoup (2018) & United States of America \\
\hline
\end{tabular}

Notes: * Study found that consumers associate food additives with harm; ** Study found that consumers associate pesticide use with degradation of quality; $* * *$ Consumers view genetically modified foods as undesirable $* * * *$ Consumers are more likely to purchase foods that come with labels which state the farm is not using hormones.

\subsubsection{Seeking quality and reflecting values}

Consumers are becoming savvier over time, when it comes to shopping for food. There are many considerations governing consumers' preferences and behaviors. International studies have found that consumers assess food quality by looking at certain factors, such as freshness, taste, nutrition, and traceability (Chamhuri \& Batt, 2015; Petrescu et al., 2020; van Rijswijk \& Frewer, 2008; Wandel \& Bugge, 1997). Neff, Spiker, Rice, Schklair, 
Greenberg, and Leib (2019) found that 'best if used by' dates are frequently considered by consumers as indicators of freshness, while 'expires on' and 'use by' dates are connected to food safety. The perception of food quality and consumers' food purchasing requirements can also be guided by their social, cultural, and economic status and demographics. Baiardi, Puglisi, and Scabrosetti (2016) found that older people and women show more interest in food quality, while parents care more about safety. Labor workers, on the other hand, considered price rather than quality. Consumers may also be interlinking food quality and safety, with safety seen as an integral part of food quality. However, more attention is paid to food quality than safety (van Rijswijk \& Frewer, 2008). Consumers also trust products based on brand loyalty, with brand identity as a crucial factor in food quality and safety perception (Lassoued \& Hobbs, 2015).

The presence of certain ingredients or substances can also affect consumers' quality perceptions. In their study on dairy consumers, Brockman and Beeren (2011) found that consumers automatically associate additives in food with harm, irrespective of whether they are aware of the benefits. In their study, consumers felt that additives in dairy products degrade the quality and, as such, should be reduced. Genetically modified food is also seen as undesirable, with consumers preferring foods that have not been genetically modified and organic (Bellows, Alcaraz \& Hallman, 2010). Also, pesticides are seen as degrading the quality of produce (My, Rutsaert, Van Loo \& Verbeke, 2017).

Personal values may also guide consumers' food preferences, and products reflecting these values (e.g., environmental concerns) are often received positively, especially by younger consumers (Lerro, Raimondo, Stanco, Nazzaro \& Marotta, 2019; Raygor, 2016; Ricci, Banterle \& Stranieri, 2018; Yu, Gibson, Wright, Neal \& Sirsat, 2017). For example, Lerro et al. (2019) found that millennials are especially concerned with social and environmental concerns, showing a willingness to switch brands based on their social and environmental initiatives. Yu et al. (2017) found that millennials frequently shop at farmers' markets because they perceive the food as of better quality. They also expressed a desire to support local food producers. This is consistent with previous studies, which found that consumers like local produce because they connect it to greater freshness and quality and want to support local agriculture (Brown, 2003; Bruhn, Vossen, Chapman, \& Vaupel, 1992). These decisions may be connected to consumers' self-interest and moral obligation (Holt, Rumble, Telg \& Lamm, 2018). A research study by Stanton (2018) found a relationship between labels which state the farm has pledged not to use hormones and purchase intent, with consumers more likely to purchase foods that come with such labels. While in the past, locally produced food was met with skepticism, consumers are now expressing the need for availability and accessibility of such foods (Bord Bia Insight Centre, 2020).

Consumers also care about animal welfare. Mayfield, Bennett, Tranter \& Wooldridge (2007) conducted a study with British, Italian and Swedish consumers and found that almost all respondents thought that animals could feel pain and that eating animal products from animals, who have had a bad life, is wrong. The majority of the study participants also expressed their preference for free-range animal products, stating that the good treatment of animals is important. This is consistent with Lagerkvist and Hess (2011), who found that consumers see animal welfare as an ethical issue for consumers. Other research found that some consumers believe that decisions about animal welfare should be made by experts and not regulated by the government (Lusk \& Norwood, 2008). Companies promoting the desired values can, therefore, benefit from aligning their corporate initiatives with consumer values (Lerro et al., 2019).

Preference for organic foods have also been noted (Bellows et al., 2010; Dumortier, Evans, Grebitus \& Martin, 2017; Lee, 2016). Choosing to purchase organic foods has been linked to health, nutrition, taste, environmental concerns, as well as situational factors, such as the presence of children in the home (Dumortier et al., 2017; Lee, 2016). In line with purchasing locally grown produce, younger and wealthier consumers were more likely to purchase organic foods (Dumortier et al., 2017). However, organic certification does not always inspire consumers' trust and influence purchase frequency, nor does it predict willingness to pay more for certified products (Dumortier et al., 2017; Xu \& Wu, 2010). Willingness to pay for certified foods was found to be related to income, age, educational level, gender, level of consumption, and awareness of traceability (Angulo \& Gil, 2007; Lagerkvist \& Hess, 2011; Xu \& Wu, 2010). 
Certain values may also guide consumers' food preferences, and products reflecting these values (e.g., environmental concerns) are often received positively, especially by younger consumers (Lerro, Raimondo, Stanco, Nazzaro \& Marotta, 2019; Raygor, 2016; Ricci, Banterle \& Stranieri, 2018; Yu, Gibson, Wright, Neal \& Sirsat, 2017). For example, Lerro et al. (2019) found that millennials are especially concerned with social and environmental concerns, showing a willingness to switch brands based on their social and environmental initiatives. Yu et al. (2017) found that millennials frequently shop at farmers' markets because they perceive the food as of better quality. They also expressed a desire to support local food producers. This is consistent with previous studies, which found that consumers like local produce because they connect it to greater freshness and quality and want to support local agriculture (Brown, 2003; Bruhn, Vossen, Chapman, \& Vaupel, 1992). These decisions may be connected to consumers' self-interest and moral obligation (Holt, Rumble, Telg \& Lamm, 2018). A research study by Stanton (2018) found a relationship between labels which state the farm has pledged not to use hormones and purchase intent, with consumers more likely to purchase foods that come with such labels. While in the past, locally produced food was met with skepticism, consumers are now expressing the need for availability and accessibility of such foods (Bord Bia Insight Centre, 2020).

\subsubsection{Over Reliance on food certifications and lack of quality information}

Certification labels (e.g., organic, free-range, halal, etc.) are frequently relied on to guide shopping decisions, whether on personal or religious grounds (Mayfield et al., 2007; Neff et al., 2019; Savelli, Murmura, Liberatore, Casolani \& Bravi 2019; Shafie \& Othman 2006). However, this may also vary among countries. A study by My et al., (2017) found that many Vietnamese consumers in their study did not know what certain food certifications mean and, as a result, many fail even to notice them when making purchases. When purchasing food, many consumers are also guided by special dietary needs or preferences. Label Insight (2016) found that consumers consider low calorie, low fat, and low sugar options, dairy or gluten-free, vegan, organic, and non-GMO foods when shopping. Many also consider where the product was made.

Consumers want to be informed and have reported sourcing information relevant to foods or food production from family members, using Google to search for independent information or from TV (Centre for Food Integrity, 2015; Mayfield et al., 2007). However, they may not always find this information. For example, Mayfield et al. (2007) found that consumers wish to be more informed than they are when it comes to animal welfare issues. The majority reported that they rely on certification labels and in-store displays at the point of purchase for this information. However, many expressed they would use available information in the media (also Label Insights, 2016). Preferred information included welfare assurance and grading, along with information on where and how an animal was raised.

This is supported by other research. In recent times, food transparency and traceability have gained more attention, with consumers increasingly wanting to know where their food comes from, choosing to purchase produce from farmers markets and expressing the desire for food transparency and information on animal welfare and safety (Centre for Food Integrity, 2015; Raygor, 2016; Yu et al., 2017). A recent survey found that $86 \%$ of grocery shoppers expressed the desire for transparency, providing easily available information. Furthermore, $75 \%$ reported being more likely to switch to brands that provide detailed information about the product, and many were prepared to pay more for transparency as it would increase trust in the brand (Shoup, 2018). Consumers connect to trace the foods they purchase to both quality and safety, but especially to safety (van Rijswijk \& Frewer, 2008). While good product information was seen as integral for making informed decisions (e.g., brand and manufacturer transparency), consumers reported they do not always trust brands to provide this information even though they expect this information to be provided (Label Insight, 2016).

Food outbreaks, which end up in the media, can also affect consumers' trust in food safety, leading to decrease in consumer confidence and higher perception of risk (Chen, 2008; De Jonge, Van Trijp, Jan Renes \& Frewer, 2007; $\mathrm{Xu} \& \mathrm{Wu}, 2010)$. For example, Angulo and Gil's (2007) study looked at the bovine spongiform encephalopathy (BSE) food scare in Spain, which led to fear and lower beef consumption. Traceability through the supply chain was implemented as a result, and consumers positively received this. The study found that confidence in food safety negatively affects perceived risks when it comes to beef, and this was sometimes affected by media 
reporting on such scandals. Some consumers may also be more affected by perceived food safety than others. For example, consumers more prone to worry, and those that are older were found to have more concerns regarding food safety (De Jonge, 2007).

Country of origin can also affect consumers' trust, with some countries seen as better at controlling bad farming and manufacturing practices (Barbarossa, De Pelsmacker, Moons \& Marcati, 2016). For example, China had multiple high-profile food fraud scandals and has in the past prioritized production volume over safety concerns, which has led to a decrease in consumer trust in the food chain (Ghose, 2014; Kendall et al., 2019; Zhang, Xu, Oosterveer, \& Mol, 2016). Food fraud is a long-standing problem that can affect safety and gain momentum, which is more difficult when good traceability is implemented within the food chain (Robson, Dean, Brooks, Haughey \& Elliott, 2020; Shears, 2008; Yiannas, 2018). Studies have found that transparency can influence brand integrity and encourage brand switching (Cambier \& Poncin, 2020; Label Insights, 2016). Therefore brands might find that implementing greater transparency leads to increased profits.

\subsection{Interviews and concept testing}

In order to understand consumers' thoughts and feelings around food quality, safety and transparency issues, we conducted six interviews with consumers based in the state of Washington, USA.

\subsubsection{Participants}

A total of 6 participants, 2 men and 4 women, who regularly shop for groceries, participated in the study. Participants were between 24 and 60 years of age and persons under the age of 18 were excluded. Participants were given information about the study, prior to the interview, allowing them the time to consider consent and general information about the study and ask for clarifications. All participants were volunteers and did not receive payment for their participation. In order to make participants feel more comfortable during the interview, all participants were given the choice of face-to-face or phone interviews (Legard, Keegan \& Ward, 2003), resulting in 3 face-to-face interviews and 3 phone interviews.

\subsubsection{Interviews}

The interviews were designed to cover as much personal experience with grocery shopping as possible, in order to provide rich data that can be used to guide further research. However, we also wanted to explore how food transparency compares to conventional food certifications (e.g., free range and organic.) In order to do this, in the first part of the interview, semi-structured questions were asked and natural story-telling was encouraged around those questions to capture rich data (Baxter, Courage, \& Caine, 2015), on what food quality means to consumers and what guides their shopping preferences. Prompts were only used to encourage participants to expand on the topics we wanted to cover. Following this, participants were asked questions covering specific topics around food safety, food transparency and trust in transparent information when it comes to food.

Finally, at the end of the interview, we tested the concept of 'transparency', in order to see if transparent products would meet consumers' needs (Dickinson \& Wilby, 1997).

The concept of the 'transparent food item' (a food item that comes with information about its origin, treatment, transportation and storage) was introduced to participants. They were asked to imagine being able to access information about food products as they shop (e.g., by scanning the product with an app). Participants were then asked to assess 'transparent food item' against products containing different attributes (e.g., food certifications instead of transparency) and indicate their purchase preferences. 


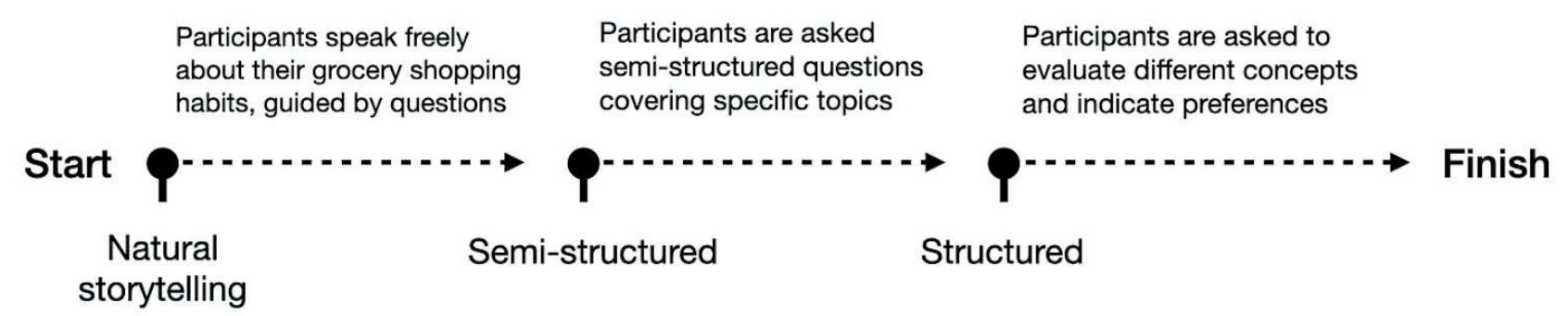

Figure 1. Interview structure

Source: compiled by authors.

This interview design proved very successful in gathering different types of data. Rich, unstructured data that was gathered at the beginning of the interview allowed us to gain unexpected insights into how people make decisions when they shop for groceries. The structured parts of the interview process, on the other hand, allowed us to explore desired topics and test the concept of transparency, whilst maintaining the integrity of the data across the participants.

All interviews were audio recorded for the purpose of the analysis. As a first step, each interview was summarized and used to extract key insights. Quotes supporting these insights were transcribed verbatim, retaining conversational features, such as hesitations and pauses but omitting repetition. To protect participants' privacy, any identifying information was changed and omitted from any written reports (King \& Horrocks, 2010; Kvale \& Brinkman, 2009).

\subsubsection{Results}

The aim of the study was to explore how consumers would react to having more transparent information about the foods they buy. This information would include origin of the product, processing and production, shipping information and safety (i.e., has the product been recalled). But first, we wanted to establish what guides participants' shopping decisions, what quality means to them and what they know about food safety.

\subsubsection{To consumers, food quality can be a subjective experience}

For almost all of the participants, quality was fresh foods that look and smell good and many participants associated quality with organic food or food that is purchased at the farmers' markets and is local.

"I typically look if it looks good.[...] I go with labelling. And if it says it's organic, I hope it's organic, because I'm paying more money for it. And it does taste different. So that's another way [to determine quality]." P1

“Local. Like picked in Washington. It's been picked recently, it got to the store quicker.” P2

"I determine quality by sight and smell, and source. If it's local, say farmers market, and the farmer's right there, person selling it. I can see where it came from, tell if it's organic or not. If it's from a big, national supermarket, I would suspect it wouldn't be as high quality as a farmers market." P5

One participant also mentioned that quality products, to him, can be those that are priced higher and have attractive packaging.

"If you're looking for a really good pasta, I would most likely go for the expensive one, which looks kind of fancy. Like, the packaging and everything looks good. I feel that would be of a higher quality than some one dollar package of spaghetti. "P2

Even stores can signal quality. One participant mentioned that she associated certain stores with quality and avoids those that, to her, seem to be low quality.

"I have this judgment and a personal preference. If I go to Whole Foods or PCC, it's quality. If I go to QFC and Fred Meyer, uhm, no." P3 
These results go hand in hand with those found in the van Rijswijk et al. (2008) study. Consumers think about quality in terms of freshness, taste and appearance, as well as origin and branding.

\subsubsection{Factors involved in shopping preferences}

Participants were asked what they consider when purchasing groceries. The majority of participants expressed that organic certification and whether food was grown locally were important factors when considering a purchase. Food that looks good, is fresh and sustainable and has good ingredients (i.e., not heavily processed) were also considerations that most of the participants evaluate as they shop for groceries (see Table 2).

Table 2. Consumer considerations which guide food purchases

\begin{tabular}{|c|c|c|c|c|c|c|}
\hline What shoppers consider while purchasing groceries & \multicolumn{6}{|c|}{ Participant } \\
\hline & P1 & $\mathbf{P 2}$ & P3 & P4 & P5 & P6 \\
\hline Source (farm/farmer)* & & & & & $\cdot$ & \\
\hline Location (local) & $\bullet$ & $\bullet$ & $\bullet$ & & $\bullet$ & $\bullet$ \\
\hline Good ingredients & $\bullet$ & & $\bullet$ & $\bullet$ & $\bullet$ & \\
\hline Organic & • & & $\bullet$ & $\bullet$ & $\bullet$ & $\bullet$ \\
\hline Freshness & & & $\bullet$ & $\bullet$ & & $\bullet$ \\
\hline Price & & $\bullet$ & & & & \\
\hline Looks good & $\bullet$ & $\bullet$ & $\bullet$ & & & $\bullet$ \\
\hline No antibiotics & $\bullet$ & & & $\bullet$ & & \\
\hline No pesticides & & & & & & $\bullet$ \\
\hline Free range/wild caught & $\bullet$ & & & $\bullet$ & & \\
\hline Sustainable & & & & $\bullet$ & $\bullet$ & $\bullet$ \\
\hline Packaging** & & & & - & & \\
\hline
\end{tabular}

Notes: *Purchases from a known farms/farmers markets **Avoiding too much packaging.

The majority of participants reported they are happy spending more money on organic and locally grown foods. Many participants cited they preferred organic as it ensures no pesticides or antibiotics and is therefore, the healthier option.

“Usually I am OK spending more for foods knowing that it's organic or comes from a local source or if it's farmers' market, where I know this person grew it, they didn't spray any chemicals on it. I am happy to spend extra, knowing that I am putting healthier food into my body. "PI

"I would pay more for local. And I would pay for some organic stuff if I think it mattered that it's organic. I think strawberries, apples... I don't want to buy the dirty dozen ${ }^{1}$ things that are known to have contaminants from pesticides and things in them" P6

One participant said that she believes 'organic' food is better, despite not knowing why.

"I just accept it as truth that organic is better. I haven't really done research, if that's actually true and I haven't really had the interest to research that but I've accepted that it is. " P3

Organic certification was especially important when purchasing meat and animal products (e.g., dairy and eggs). All of the participants said that, when purchasing meat, eggs or fish, they prefer to go for organic, grass fed or wild caught.

"If I can afford it, then I definitely would want to care and know where it's coming from, especially for meat. Because I don't eat a lot of meat and when I do, I like to know where it came from, how did they raise this animal, how did they kill the animal [...] For produce, I don't care as much where it comes from, because it's just vegetables. " P1

\footnotetext{
${ }^{1}$ Items identified as containing high pesticide levels by Environmental Working Group (2010). Includes strawberries, spinach, kale, nectarines, apples, grapes, peaches, cherries, pears, tomatoes, celery, potatoes and hot peppers.
} 
SocioEconomic Challenges, Volume 4, Issue 4, 2020

ISSN (print) - 2520-6621, ISSN (online) - 2520-6214

"I go out of my way to spend more money on any animal produce. I like the cage-free, organic eggs, I like grass fed beef and wild caught salmon. "P2

"I would never buy a dairy product that isn't organic." P4 (vegetarian but eats dairy)

For many participants this was down to farming practices and ethos and animal welfare.

“I have a spiritual connection to animal products, so I don't want to consume meat that contributed to suffering of animals.” P1

"I buy eggs that say pasture raised because it's better conditions for the chickens." P3

Some participants expressed preference for local foods, which were seen as more sustainable and better for the environment.

"It comes to helping local economy. It's better for the environment, it's better for the Earth, it's better for what I consider the natural economy, which helps promote locally sourced, lower carbon intensive food products." P5

\subsubsection{Consumers are confused about food safety}

One of our aims was to assess the level of knowledge consumers had around food safety, such as food recalls and food outbreaks. When asked what food safety means to them, participants offered varying perspectives. Some of the participants trusted that food they purchase in the grocery stores is safe.

"I guess I never purchased the food thinking from a safety perspective." PI

"I just assume that anything that's sold in the store is safe to eat." P2

"I'm gonna have to assume that it's safe, because it's at the grocery store that I go to." P6

Others did not know what food safety refers to and connected it to artificial ingredients, allergies and restaurant ratings.

"Let's say if I have an allergy. If I was allergic to nuts, food safety would be 'does the food contain nuts or something I'm allergic to'." $\mathrm{PI}$

"Food safety? Oh, I don't even know. It [the food] met some standard, but I don't know what those standards are. But somebody somewhere had some standards and this food passed." P3

Only one participant associated food safety with use by dates and good farming practices, both of which have a potential to affect food safety.

"Obviously in date and not having been farmed in an unsafe environment. For example meat or fish being farmed in an environments that are overcrowded." P4

However, when food safety was explained, by outlining that it means the food is safe to eat, is free from illness causing bacteria, has not been tampered with or recalled, all participants voiced that food safety is extremely important. They also expressed that being able to find out whether the food they are about to consume has been recalled would be essential.

"That would be great because it would save me from eating something that could be toxic for my body" PI

“Oh yeah, that would be excellent. I don't wanna buy anything that's been recalled." P6

However, one participants said that she would prefer not to know about recalls, because thinking about whether the food has been recalled and assessing the risks connected to eating recalled food on a regular basis would require cognitive effort. This was seen as counterproductive when it comes to food, because to her, food is an experience and there is a certain amount of risk connected to eating food.

"It's too much information. And I wouldn't like that. If I get sick, I get sick, my body cleans it out, stay home for couple of days and it was what it was. Too much information can create unnecessary scare. I would rather eat something that's been recalled and not know it, and get sick and deal with that. Because that, to me, feels like a more natural way to live." P3 


\subsubsection{Testing 'transparent food' concept}

In order to explore consumer needs regarding transparency, the second part of the interview consisted of concept testing. Participants were asked to imagine a meat product that comes without certifications (such as free range and organic) but all the information about that product is available, starting from its origin (i.e., farm where the animal was raised) to what processing it went through, transportation logistics, such as miles and days travelled and conditions during transit. They were then asked to compare this 'transparent' item to an identical item, which may contain certifications but lacks transparency and specify which item they would prefer. Different attributes were introduced during this process (e.g., good farming practices) in order to see what matters to consumers (see Table 3).

Table 3. Comparing Transparency to Traditional certifications; Participants' Preferences

\begin{tabular}{|l|l|l|}
\hline \multicolumn{1}{|c|}{ Comparison } & \multicolumn{1}{c|}{ Transparency } & \multicolumn{1}{c|}{ Traditional certifications } \\
\hline $\mathbf{1}^{\text {st }}$ pair & Transparent and Bad farming practices & Not transparent and Organic/free range* \\
\hline $\mathbf{2}^{\text {nd }}$ pair & Transparent and Organic/free range* & Not transparent and Organic/free range \\
\hline $\mathbf{3}^{\text {rd }}$ pair & Transparent and Good farming practices* & Not transparent and Organic/free range \\
\hline
\end{tabular}

Note: *Participants’ preference.

Overall, all participants voiced that transparency, when it comes to foods, is a good idea. They said it would empower them to make optimal decisions when it comes to food purchases, allowing them to see where the food comes from and how it was grown or raised.
"It would be a life changer. I would feel like some sort of control over my decisions. Right now I am buying whatever is on the shelf and I have no idea where it comes from. I am taking it based on the look. This would give me a little bit more power in my decision, which would be awesome" P1
"It would heavily influence my shopping decisions. It would be a complete 180 if I could scan some package of meat and see the entire process of where it was grown, and where it was packaged and all that." P2
"In fact, my husband and I were talking: wouldn't it be great if there were apps that could scan the product and it would immediately tell you its life basically, from start to finish." P4

Although participants liked the idea of transparency, they voiced their preference for organic and free range methods. These certifications meant that the animal welfare was upheld at the farm and this was preferable as it aligned with personal values. Participants said they would only prefer a product that was not organic or free range, if it came with information supporting their values on good farming practices and animal welfare. A product that is transparent but which is seen to be low quality (e.g., intensively farmed) would not be desirable just because it was transparent.

"For me organic means slightly more nutritious, healthier for me. And nutritious and healthy is what dictates my shopping decisions most of the time." P2

One participant liked the idea of transparency because he thought organic certification does not always equate good farming practices.
"It's pretty low bar to be certified organic. And if there was another classification or another methodology that gave me more information than just national certification of organic, I feel that would provide better information to me as a consumer." P5

This was echoed by other participants. They voiced that transparency would allow them to evaluate farming practices. One participant said that she would prefer organic and free range products over transparent because that signifies better farming practices, but she also expressed doubt over the credibility of this information.

\footnotetext{
"Organic and free range. Because of the life of the animal, I'm assuming. And it's an assumption because they could label it that way but I don't know how that chicken was treated. But I like to believe when I see labels like organic and free range, that the quality of life of the animal is better. " P3
}

The findings of the concept testing supported what the participants told us earlier in the interview. Organic and free range certifications are important because they signify good farming practices. All of the participants thought 
that transparency would allow them to confirm this information, as well as allow them to explore deeper information about the products they consume.

\section{Discussion and conclusion}

This interview study aimed to explore food consumers' opinions on food quality and safety and introduce the concept of 'food transparency,' to see how transparency compares to information consumers consider when purchasing food, including organic and free-range certifications. Consistent with Lassoued and Hobbs (2015) and Lerro et al. (2019), participants in our study associated certain brands and grocery stores with quality, choosing to shop in grocery stores, which they perceived to reflect the quality and their social and environmental concerns. Consistent with previous research (Holt et al., 2018; Raygor, 2016; Stanton, 2018; Yu et al., 2017), local produce is fresher, better quality and environmentally friendly and where possible, our participants tried sourcing local produce because they perceived this to be more 'ethical.' Participants stressed the importance of choosing organic and free-range animal products, citing a lack of hormones as a safer option. However, people tend to recall more food outbreaks affecting meat and fish (De Jonge, 2007), which may affect how careful they are with animal products.

Consistent with Shoup (2018), participants expressed excitement at the thought of being able to access transparent information about food but questioned the credibility of this information. Many voiced that transparent information needs to be congruous with their beliefs and values (e.g., good farming practices), consistent with previous findings (see Centre for Food Integrity, 2015). If consumers can access the information about the origin of the foods they consume, especially animal products, they can be reassured that animal welfare was upheld and safe farming practices employed, increasing consumer confidence.

Participants were initially confused about food safety, which had to be explained. Many voiced that they trust grocery stores to supply safe foods, indicating a lack of general awareness of foodborne illnesses and trust in stores to manage food safety (Angulo \& Gill, 2007). Additionally, some participants in our study found thinking about recalls stressful. This suggests that consumers place trust in grocery stores to keep them safe, because thinking about food safety may be overwhelming for some consumers, creating anxiety.

While the participants in our study expressed low concern for food safety and increased trust in the supermarkets and food producers, especially when the product came with organic certification, they showed concern about the use of pesticides and hormones in farming practices. This made them fall somewhere between trusting and apprehensive consumers, who were found to have concerns about foodborne illness and the use of pesticides, hormones, and additives (Kennedy et al., 2008). Participants trusted organic and free-range certifications, linking them to good farming practices, lack of pesticides, additives, hormones, and better animal welfare. These beliefs were upheld even in the absence of any factual information. For example, one participant cited avoiding the 'dirty dozen,' a list of products that contained high pesticide levels (Environmental Working Group, 2010). However, a consequent study examining produce on the 'dirty dozen list' found pesticide levels to be safe, and the risk of exposure to pesticides for those produce items negligible, concluding that organic substitutes do not love consumer risks (Winter \& Katz, 2011). This may mean that certain aspects of transparency, such as the disclosed use of pesticides, could needlessly scare consumers who are already confused over the safety of pesticides.

Although small, the present study unearthed some critical insights on factors that guide food shopping preferences and underlie consumers' reasoning when it comes to what they deem necessary when it comes to foods they eat. Consumers are guided by their values and perceptions of food quality, which was not universal, but rather a very individual concept, based on beliefs and experiences.

The study utilized the concept testing methodology to compare the relatively novel concept of food transparency against the established food certifications. The results indicated that consumers place trust in organic and freerange labeling but are willing to try better ways of assessing the foods they consume because they are aware that their trust is based on assumptions rather than facts. Additionally, food safety can be an overwhelming topic, and consumers may purposely be relying on the stores to make sure the food is safe to avoid having to think about it.

\section{Limitations and future research}


Due to the small sample size, these results cannot be generalized across a wider population. Since all of our participants live in Washington, there is a possibility that research conducted with consumers in other parts of the USA and/or other countries, especially those with different cultural and societal backgrounds, may yield different results. Most of the participants in our study were happy to pay more for transparent products. However, this may not be representative of other food consumers, especially those who may be shopping on a budget. For example, Lagerkvist and Hess (2011) argue that implementing good animal welfare can harm some consumers, who may not be able to afford the associated increase in price that typically comes with animal-friendly farming practices. It is possible that our sample did not consist of people who worry about this.

Since this was a small exploratory study, we did not concentrate on collecting in-depth demographic data, such as social and economic indicators, on exploring this further. Future studies may want to explore the concept of transparency accounting for demographic factors and concentrating on sampling participants from different geographical areas. Future studies may also want to test the concept of transparency against other food certifications (e.g., halal, kosher, gluten-free, etc.) to identify other areas in which transparency can help consumers make optimal decisions.

Funding: self-funded.

Author Contributions: conceptualization, Martina Dove; data curation, Martina Dove; formal analysis, Martina Dove; funding acquisition, Martina Dove, Adhithya Balasubramanian, Badri G. Narayanan; investigation, Martina Dove; methodology, Martina Dove; project administration, Badri G. Narayanan; resources, Martina Dove, Adhithya Balasubramanian; software, Martina Dove; supervision, Badri G. Narayanan; validation, Martina Dove; visualization, Martina Dove; writing - original draft, Martina Dove, Adhithya Balasubramanian, Badri G. Narayanan; writing - review \& editing, Martina Dove, Adhithya Balasubramanian, Badri G. Narayanan.

\section{References}

1. Angulo, A. M., \& Gil, J. M. (2007). Risk perception and consumer willingness to pay for certified beef in Spain. Food Quality and Preference, 18(8), 1106-1117. doi: 10.1016/j.foodqual.2007.05.008.

2. Baiardi, D., Puglisi, R., \& Scabrosetti, S. (2016). Individual attitudes on food quality and safety: Empirical evidence on EU countries. Food quality and preference, 49, 70-74. doi: 10.1016/j.foodqual.2015.11.011.

3. Barbarossa, C., De Pelsmacker, P., Moons, I., \& Marcati, A. (2016). The influence of country-of-origin stereotypes on consumer responses to food safety scandals: The case of the horse meat adulteration. Food Quality and Preference, 53, 71-83. Available at: http://hdl.handle.net/1854/LU-8524420.

4. Baxter, K., Courage, C., \& Caine, K. (2015). Understanding your users: a practical guide to user research methods. Morgan Kaufmann. Available at: https://www.amazon.com/Understanding-Your-Users-InteractiveTechnologies/dp/0128002328.

5. Bellows, A. C., Alcaraz, G., \& Hallman, W. K. (2010). Gender and food, a study of attitudes in the USA towards organic, local, US grown, and GM-free foods. Appetite, 55(3), 540-550. doi: 10.1016/j.appet.2010.09.002.

6. Bord Bia Insight Centre. (2017). Local food, Understanding Consumer Attitudes. Available at: https://www.bordbia.ie/globalassets/bordbia2020/industry/insights/consumer-insights/local-foodunderstanding-consumer-attitudes-february-2017.pdf

7. Brockman, C., \& Beeren, C. J. M. (2011). Additives in dairy foods consumer perceptions of additives in dairy products. Encyclopedia of Dairy Sciences, 41-48 doi: 10.1016/b978-0-12-374407-4.00003-0.

8. Brown, C. (2003). Consumers' preferences for locally produced food: A study in southeast Missouri. American Journal of Alternative Agriculture, 18(4), 213-224. doi: 10.1079/ajaa200353.

9. Bruhn, C., Vossen, P., Chapman, E., \& Vaupel, S. (1992). Consumer attitudes toward locally grown produce. California Agriculture, 46(4), 13-16. DOI: 10.3733/ca.v046n04p13.

10. Cambier, F., \& Poncin, I. (2020). Inferring brand integrity from marketing communications: The effects of brand transparency signals in a consumer empowerment context. Journal of Business Research, 109, 260270. doi: https://doi.org/10.1016/j.jbusres.2019.11.060. 
11. Chamhuri, N., \& Batt, P. J. (2015). Consumer perceptions of food quality in Malaysia. British Food Journal, 117,1168-1187. doi: 10.1108/bfj-08-2013-0235.

12. Chen, M. F. (2008). Consumer trust in food safety - a multidisciplinary approach and empirical evidence from Taiwan. Risk Analysis: An International Journal, 28(6), 1553-1569. doi: 10.1111/j.15396924.2008.01115.x.

13. de Jonge, J., Frewer, L., van Trijp, H., Jan Renes, R., de Wit, W. and Timmers, J. (2004). Monitoring consumer confidence in food safety: an exploratory study. British Food Journal, 106(10/11), pp. 837-849. https://doi.org/10.1108/00070700410561423.

14. De Jonge, J., Van Trijp, H., Jan Renes, R., \& Frewer, L. (2007). Understanding consumer confidence in the safety of food: Its two-dimensional structure and determinants. Risk Analysis: An International Journal, 27(3), 729-740. doi: 10.1111/j.1539-6924.2007.00917.x.

15. Dumortier, J., Evans, K. S., Grebitus, C., \& Martin, P. A. (2017). The influence of trust and attitudes on the purchase frequency of organic produce. Journal of International Food \& Agribusiness Marketing, 29(1), 4669. Available at: https://core.ac.uk/download/pdf/129149167.pdf.

16. Environmental Working Group (2010). EWG's Shoppers Guide to Pesticides ${ }^{\mathrm{TM}}$. Environmental Working Group, Washington, DC, USA. Available at: http://www.foodnews.org.

17. Ghose, B. (2014). Food security and food self-sufficiency in China: from past to 2050. Food and Energy Security, 3(2), 86-95. Available at: https://doi.org/10.1002/fes3.48.

18. Holt, J., Rumble, J. N., Telg, R., \& Lamm, A. (2018). Understanding Consumer Intent to Buy Local Food: Adding Consumer Past Experience and Moral Obligation Toward Buying Local Blueberries in Florida Within the Theory of Planned Behavior. Journal of Applied Communications, 102(2), 5. doi: 10.4148/10510834.2203.

19. Kendall, H., Kuznesof, S., Dean, M., Chan, M. Y., Clark, B., Home, R., ... \& Frewer, L. (2019). Chinese consumer's attitudes, perceptions and behavioural responses towards food fraud. Food Control, 95, 339-351. doi: 10.1016/i.foodcont.2018.08.006.

20. King, N., \& Horrocks, C. (2010). An introduction to interview data analysis. Interviews in qualitative research, 142-174. Available at: https://www.scirp.org/(S(i43dyn45teexjx455qlt3d2q))/reference/ReferencesPapers.aspx?ReferenceID=9193 $\underline{08}$.

21. Kvale, S., \& Brinkmann, S. (2009). Learning the craft of qualitative research interviewing. Thousand Oaks. CA. Sage Publications. Available at: https://uk.sagepub.com/en-gb/eur/interviews/book239402.

22. Label Insight (2016) How Consumer Demand for Transparency is Shaping the Food Industry. Food Revolution Study. Available at: https:/www.labelinsight.com/hubfs/Label Insight-Food-RevolutionStudy.pdf?hsCtaTracking=fc71 fa82-7e0b-4b05-b2b4-de1ade992d33\%7C95a8befc-d0cc-4b8b-8102529d937eb427

23. Lagerkvist, C. J., \& Hess, S. (2011). A meta-analysis of consumer willingness to pay for farm animal welfare. European Review of Agricultural Economics, 38(1), 55-78. doi: 10.1093/erae/jbq043.

24. Lassoued, R., \& Hobbs, J. E. (2015). Consumer confidence in credence attributes: The role of brand trust. Food Policy, 52, 99-107. doi: 10.1016/j.foodpol.2014.12.003.

25. Lee, H. J. (2016). Individual and situational determinants of US consumers' buying behavior of organic foods. Journal of International Food \& Agribusiness Marketing, 28(2), 117-131. doi: 10.1080/08974438.2015.1035471.

26. Legard, R., Keegan, J., \& Ward, K. (2003). In-depth interviews. Qualitative research practice: A guide for social science students and researchers, 6(1), 138-169. Available at: https://mthoyibi.files.wordpress.com/2011/10/qualitative-research-practice a-guide-for-social-sciencestudents-and-researchers jane-ritchie-and-jane-lewis-eds 20031.pdf.

27. Lerro, M., Raimondo, M., Stanco, M., Nazzaro, C., \& Marotta, G. (2019). Cause related marketing among millennial consumers: The role of trust and loyalty in the food industry. Sustainability, 11(2), 535. doi: $\underline{10.3390 / \text { su11020535. }}$. 
28. Lusk, J. L., \& Norwood, F. B. (2008). A survey to determine public opinion about the ethics and governance of farm animal welfare. Journal of the American Veterinary Medical Association, 233(7), 1121-1126.. doi: 10.2460/javma.233.7.1121.

29. Mayfield, L. E., Bennett, R. M., Tranter, R. B., \& Wooldridge, M. J. (2007). Consumption of welfare-friendly food products in Great Britain, Italy and Sweden, and how it may be influenced by consumer attitudes to, and behaviour towards, animal welfare attributes. International Journal of Sociology of Food and Agriculture, 15(3), 59-73. Available at: https://www.researchgate.net/publication/228806876_Consumption_of_WelfareFriendly_Food_Products_in_Great_Britain_Italy_and_Sweden_and_How_It_May_Be_Influenced_by_Con sumer Attitudes To and Behaviour Towards Animal Welfare Attributes.

30. My, N. H., Rutsaert, P., Van Loo, E. J., \& Verbeke, W. (2017). Consumers' familiarity with and attitudes towards food quality certifications for rice and vegetables in Vietnam. Food Control, 82, 74-82. doi: 10.1016/j.foodcont.2017.06.011.

31. Neff, R. A., Spiker, M., Rice, C., Schklair, A., Greenberg, S., \& Leib, E. B. (2019). Misunderstood food date labels and reported food discards: A survey of US consumer attitudes and behaviors. Waste management, 86 , 123-132. doi: 10.1016/j.wasman.2019.01.023.

32. Petrescu, D. C., Vermeir, I., \& Petrescu-Mag, R. M. (2020). Consumer Understanding of Food Quality, Healthiness, and Environmental Impact: A Cross-National Perspective. International Journal of Environmental Research and Public Health, 17(1), 169. doi: 10.3390/ijerph17010169.

33. Raygor, A. D. (2016). The theory of planned behavior: Understanding consumer intentions to purchase local food in Iowa. Graduate Theses and Dissertations, 15798. . doi: 10.31274/etd-180810-5426.

34. Ricci, E. C., Banterle, A., \& Stranieri, S. (2018). Trust to go green: an exploration of consumer intentions for eco-friendly convenience food. Ecological economics, 148, 54-65. doi: 10.1016/j.ecolecon.2018.02.010.

35. Robson, K., Dean, M., Brooks, S., Haughey, S., \& Elliott, C. (2020). A 20-year analysis of reported food fraud in the global beef supply chain. Food Control, 107310. doi: 10.1016/j.foodcont.2020.107310.

36. Savelli, E., Murmura, F., Liberatore, L., Casolani, N., \& Bravi, L. (2019). Consumer attitude and behaviour towards food quality among the young ones: Empirical evidences from a survey. Total Quality Management \& Business Excellence, 30(1-2), 169-183. doi: 10.1080/14783363.2017.1300055.

37. Shafie, S., \& Othman, M. N. (2006, September). Halal certification: an international marketing issues and challenges. In Proceeding at the International IFSAM VIIIth World Congress (pp. 28-30). Available at: https://hrmars.com/papers submitted/3498/Key Challenges and Issues Consumer Face in Consuming Halal_Product.pdf.

38. Shears, P. (2010). Food fraud-a current issue but an old problem. British Food Journal, 112(2), 198-213. doi: $10.1108 / 00070701011018879$.

39. Shoup, M. (2018, November 30). How are consumers thinking about transparency? FMI and Label Insight explain. Food Navigator -USA, Available at: https://www.foodnavigator-usa.com.

40. Stanton, J. (2018). An Analysis of Consumers' Preferences between Locally Grown/Processed Food and Organic Food. Current Investigations in Agriculture and Current Research, 4(1). doi: 10.32474/ciacr.2018.04.000180.

41. The Centre for food integrity. (2015). A clear view of transparency and how it builds consumer trust, 2015 Consumer Trust Research. http://www.foodintegrity.org/wp-content/uploads/2018/03/CFI-2015-ConsumerTrust-Research-Booklet.pdf.

42. van Rijswijk, W., \& Frewer, L. J. (2008). Consumer perceptions of food quality and safety and their relation to traceability. British Food Journal, 110(10), 1034-1046. https://doi.org/10.1108/00070700810906642.

43. Wandel, M., \& Bugge, A. (1997). Environmental concern in consumer evaluation of food quality. Food quality and preference, 8(1), 19-26. doi: 10.1016/s0950-3293(96)00004-3.

44. Winter, C. K., \& Katz, J. M. (2011). Dietary exposure to pesticide residues from commodities alleged to contain the highest contamination levels. Journal of toxicology, 2011. doi: 10.1155/2011/589674.

45. Xu, L., \& Wu, L. (2010). Food safety and consumer willingness to pay for certified traceable food in China. Journal of the Science of Food and Agriculture, 90(8), 1368-1373. doi: 10.1002/jsfa.3985.

46. Yiannas, F. (2018). A new era of food transparency powered by blockchain. Innovations: Technology, Governance, Globalization, 12(1-2), 46-56. doi: 10.1162/inov a 00266 . 
47. Yu, H., Gibson, K. E., Wright, K. G., Neal, J. A., \& Sirsat, S. A. (2017). Food safety and food quality perceptions of farmers' market consumers in the United States. Food Control, 79, 266-271. doi: 10.1016/j.foodcont.2017.04.010.

48. Zhang, L., Xu, Y., Oosterveer, P., \& Mol, A. P. (2016). Consumer trust in different food provisioning schemes: evidence from Beijing, China. Journal of Cleaner Production, 134, 269-279. doi: https://doi.org/10.1016/j.jclepro.2015.09.078. 